\title{
Synthesis of metallic aluminum particles by electrolysis in aqueous solution
}

\author{
Takefumi Hosoya ${ }^{1}$, Takehiro Yonezawa ${ }^{2}$, Noriko Yamauchi ${ }^{1}$, Kouichi Nakashima ${ }^{1 *}$ and Yoshio Kobayashi ${ }^{1 *}$
}

\begin{abstract}
The present work proposes a method for fabricating metallic Al particles in aqueous solution. An aqueous colloidal solution was prepared from an aqueous aluminum nitrate nonahydrate solution by electrolysis using metallic $\mathrm{Al}$ plates as the anode and cathode under ultrasonic irradiation in water at $25-45^{\circ} \mathrm{C}$. The sizes of the particles in the colloidal solutions prepared at 25,35 , and $45^{\circ} \mathrm{C}$ were $76.3,77.0$, and $84.7 \mathrm{~nm}$, respectively. The powder obtained from the colloidal solution prepared at $25^{\circ} \mathrm{C}$ was not crystalline. By contrast, the powders obtained from the colloidal solutions prepared at 35 and $45^{\circ} \mathrm{C}$ had a crystal structure of cubic Al and crystal sizes of 55.7 and $59.3 \mathrm{~nm}$, respectively. Thus, elevated temperatures promoted both particle growth and crystal growth, which was explained by higher temperatures increasing the frequency and energy of particle collisions. The metallic Al particles were chemically stable in both an aqueous solution and the ambient atmosphere. The chemically stable metallic Al particles are expected to be used as sources for fabricating materials related to fuels, energy storage, and pigments.
\end{abstract}

Keywords: Aluminum, Particle, Aqueous colloidal solution, Electrolysis

\section{Introduction}

Nanoparticles and microparticles of metallic materials are widely known to exhibit properties that differ from those of the corresponding bulk materials. Hence, metallic particles are used in fields related to catalysis, optics, and biotechnology [1-3]. Metallic Al particles have also been investigated for potential applications as fuels, energy storage materials, and pigments [4-6]. Many reported methods for synthesizing metallic Al particles involve the electrical evaporation or explosion of metallic $\mathrm{Al}$ wire in a gaseous medium, which is a well-known gasphase process for synthesizing particles [7-12]. Although this gas-phase process works well, it requires equipment that is expensive, consumes a large amount of electric power, and is complicated and dangerous to perform.

\footnotetext{
*Correspondence: kouichi.nakashima.pilot@vc.ibaraki.ac.jp; yoshio.kobayashi. yk@vc.ibaraki.ac.jp

${ }^{1}$ Department of Materials Science and Engineering, Graduate School of Science and Engineering, Ibaraki University, 4-12-1 Naka-narusawa-cho, Hitachi, Ibaraki 316-8511, Japan

Full list of author information is available at the end of the article
}

An alternative method to produce metallic particles is liquid-phase reactions. Most such reactions involve the reduction of metal ions in an aqueous phase. This process can easily produce a large amount of metallic particles and is therefore suitable for industrial production. Particles of noble metals such as $\mathrm{Au}, \mathrm{Pt}$, and $\mathrm{Ag}$ can be synthesized via the reduction of metal ions in aqueous solution [13-15]. However, the synthesis of less-noble metals in aqueous solution is difficult. For example, the corrosion of metallic $\mathrm{Al}$ in aqueous electrolytes leads to oxidation of metallic $\mathrm{Al}$ by the reaction $2 \mathrm{Al}+6 \mathrm{H}_{2} \mathrm{O} \rightarrow 2 \mathrm{Al}(\mathrm{OH})_{3}+3 \mathrm{H}_{2} \uparrow[16]$, which makes both the synthesis and long-term storage of metallic $\mathrm{Al}$ particles difficult. Metallic Al particles can be synthesized via a process based on the reduction of $\mathrm{Al}^{3+}$ ions in organic solvents $[17,18]$. The organic solvents are used to inhibit the oxidation derived from aqueous electrolytes. However, the use of organic solvents increases the environmental impact.

Typical methods for producing metals and metal alloys are electrolytic processing (electrolysis) techniques such as electrodeposition and electroplating [19-23]. The 
electrolytic deposition of metallic $\mathrm{Al}$ has been reported [24-26]. The electrolysis process does not usually involve reducing reagents and therefore can increase the purity of the metal. Electrolysis usually forms a metallic film on the electrode via the deposition of metal nanoparticles. If the metallic particles deposited onto the electrode can be dispersed in the electrolyte, the dispersion can yield a colloidal solution of metallic particles. From this viewpoint, several researchers have synthesized metallic particles using electrolysis [27-29]. Methods for the electrolytic synthesis of metallic $\mathrm{Al}$ particles, in particular, have also been reported [30-32]. In these methods, an organic solvent, ionic liquid, and strong reducing reagent are used, which creates a large environmental load, introduces high costs, poses a danger to human health and the environment, and leads to adulteration of the product by impurities that originate from the reducing reagent. Unsurprisingly, the synthesis of metallic $\mathrm{Zn}$ particles in water is also challenging. Nevertheless, our research group has synthesized metallic $\mathrm{Zn}$ particles via electrolysis in aqueous solution.

In the present study, we extend our method used to prepare metallic-Zn-particle colloidal solutions in water by electrolysis to prepare high-purity metallic $\mathrm{Al}$ particles via a simple method with low environmental impact, which is also challenging.

\section{Experimental}

Materials

Aluminum nitrate nonahydrate $\left(\mathrm{Al}\left(\mathrm{NO}_{3}\right)_{3} \cdot 9 \mathrm{H}_{2} \mathrm{O}\right)(98.0 \%$, Kanto Chemical Co.) was used as received as the starting reagent for preparing metallic $\mathrm{Al}$ particle colloidal solutions. Metallic Al plates with dimensions of $20 \times 75 \times 0.5$ $\mathrm{mm}^{3}$ were used as the electrodes. A commercial metallic $\mathrm{Al}$ plate (purity: $99.7 \%$, dimensions: $45 \times 120 \times 0.5 \mathrm{~mm}^{3}$, code \#: 1-126-0119, Kenis) was divided into metallic Al plates with the desired size. All the aqueous solutions were prepared using water purified by ion exchange and distillation with an Advantec RFD372NC water distillation apparatus.

\section{Preparation}

Figure 1 shows an illustration of set-up of fabrication of metallic $\mathrm{Al}$ nanoparticles by electrolysis in aqueous solution. The electrolytic solution was a $0.1 \mathrm{M} \mathrm{Al}\left(\mathrm{NO}_{3}\right)_{3}$ aqueous solution prepared using purified water, in which the oxygen was removed by $\mathrm{N}_{2}$ bubbling. One hundred milliliters of the electrolyte solution was placed in a beaker with a capacity of $100 \mathrm{~mL}$. Electrolysis was carried out at room temperature using a two-electrode system with a constant current in the electrolytic solution. The $\mathrm{Al}$ plates were used as both the anode and the cathode. At the anode, $\mathrm{Al}^{3+}$ should be supplied to the electrolyte

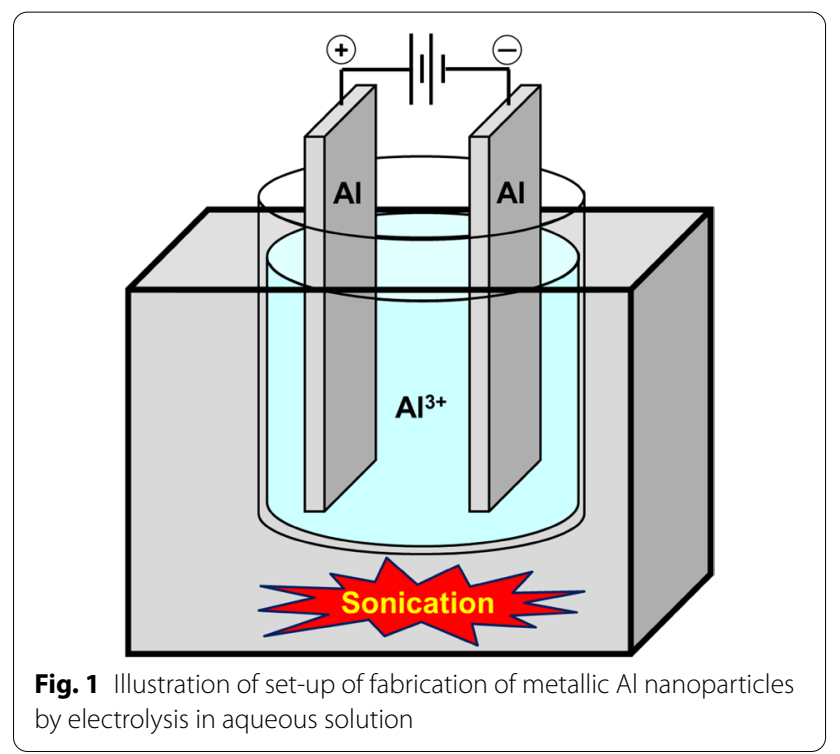

solution, as represented by the reaction $\mathrm{Al} \rightarrow \mathrm{Al}^{3+}+3 \mathrm{e}^{-}$. At the cathode, the reaction $\mathrm{Al}^{3+}+3 \mathrm{e}^{-} \rightarrow \mathrm{Al}$ should occur, where $\mathrm{Al}^{3+}$ is supplied from the reagent used to prepare the electrolyte and by the reaction $\mathrm{Al} \rightarrow \mathrm{Al}^{3+}+3 \mathrm{e}^{-}$at the anode. Metallic $\mathrm{Al}$ should be produced through deposition of $\mathrm{Al}$ nuclei followed by growth of the nuclei into $\mathrm{Al}$ nanoparticles on the cathode. The two electrodes were submerged in $2 \mathrm{~cm}$ of the electrolytic solution such that the distance between them was $2 \mathrm{~cm}$. The voltage was applied using an A\&D AD8724D DC stabilized power supply to maintain a current constant of 1.0 A. The electrolysis time was $60 \mathrm{~min}$. To disperse the $\mathrm{Al}$ nanoparticles deposited onto the cathode into the electrolytic solution prior to the formation of metallic bulk $\mathrm{Al}$, the bottom of the beaker was irradiated with ultrasonic waves generated by a Honda Electronics W-113 ultrasonic cleaner (oscillation frequency: $28 \mathrm{kHz}$ ) during electrolysis.

\section{Characterization}

The morphology and crystal structure of the particles were investigated by transmission electron microscopy (TEM) and X-ray diffraction (XRD), respectively. TEM imaging was performed using a JEOL JEM-2100 microscope operating at $200 \mathrm{kV}$. The TEM samples were prepared by dropping the colloidal solution onto a collodion-coated $\mathrm{Cu}$ grid and evaporating its dispersant. The volume-averaged particle size and the standard deviation of the particle size distribution were determined using dozens of particle diameters measured in the TEM images. The XRD measurements were carried out using a Rigaku Ultima IV X-ray diffractometer with a $\mathrm{CuK} \alpha$ radiation source operated at $40 \mathrm{kV}$ and $30 \mathrm{~mA}$. 
The XRD samples were powders of the particles. The particles in the colloidal solution were washed by repeated centrifugation and decantation to remove the supernatant, followed by the addition of water and redispersion by shaking using a vortex mixer. The washing process was performed three times, and the particle powder was obtained by centrifuging the colloidal solution, removing its supernatant by decantation in the third washing process, and drying the slightly wet particle powder in a Yamato DP-31 vacuum drying oven equipped with an oilsealed rotary vacuum pump (ULVAC GCD-136X).

\section{Results and discussion}

\section{Electrolysis at room temperature $\left(25^{\circ} \mathrm{C}\right)$}

Figure 2a shows a photograph of the electrolytic solution before electrolysis. The solution was transparent at this point. Figure $2 \mathrm{~b}$ shows a photograph of the electrolytic solution prepared by electrolysis at $25^{\circ} \mathrm{C}$. The transparent electrolytic solution became a slightly opaque and grayish colloid solution after electrolysis. No significant precipitation occurred after a few hours of preparation, as far as the naked eye could determine. The solution could therefore be regarded as colloidally stable. The opaqueness implied the production of nanoparticles that caused light scattering.

Figure 3a shows a TEM image of particles contained in the colloidal solution. Several particles were observed, and their size was $76.3 \pm 30.2 \mathrm{~nm}$. Pattern (a) in Fig. 4 shows the XRD pattern of the particles obtained at room temperature. No remarkable peaks were detected, which indicates that the particles were either amorphous or crystallites that were too fine to be detected.

\section{Electrolysis under heating}

Figure 2c, d show photographs of the electrolytic solutions prepared after the electrolysis at 35 and $45{ }^{\circ} \mathrm{C}$, respectively. Like the product obtained at $25{ }^{\circ} \mathrm{C}$, those obtained at 35 and $45{ }^{\circ} \mathrm{C}$ were slightly opaque, grayish, and colloidally stable solutions. Figure $3 \mathrm{~b}$, c show TEM images of particles in the colloid solutions. The particle sizes were $77.0 \pm 31.0 \mathrm{~nm}$ for product obtained at $35^{\circ} \mathrm{C}$ and $84.7 \pm 38.2 \mathrm{~nm}$ for those obtained at $45{ }^{\circ} \mathrm{C}$. Thus, the particle size increased with increasing temperature of the electrolytic solution. The particles collided with greater

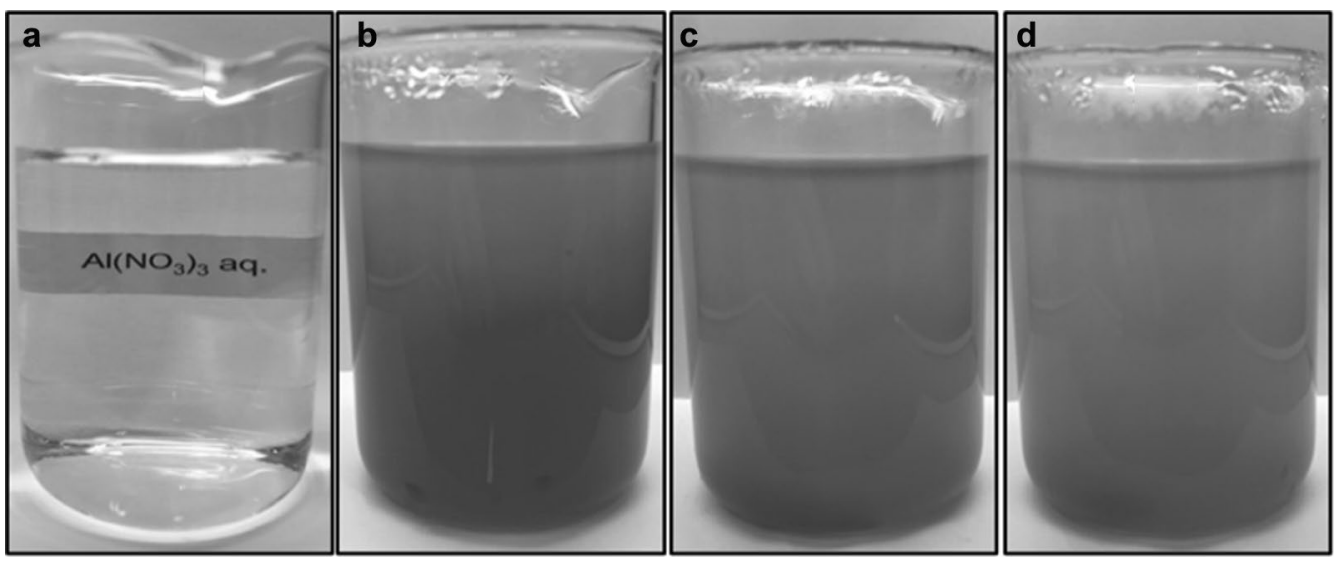

Fig. 2 Photographs of a $\mathrm{Al}\left(\mathrm{NO}_{3}\right)_{3}$ aqueous solution and colloidal solutions prepared by electrolysis at $\mathbf{b} 25^{\circ} \mathrm{C}$, $\mathbf{c} 35^{\circ} \mathrm{C}$, and $\mathbf{d} 45^{\circ} \mathrm{C}$

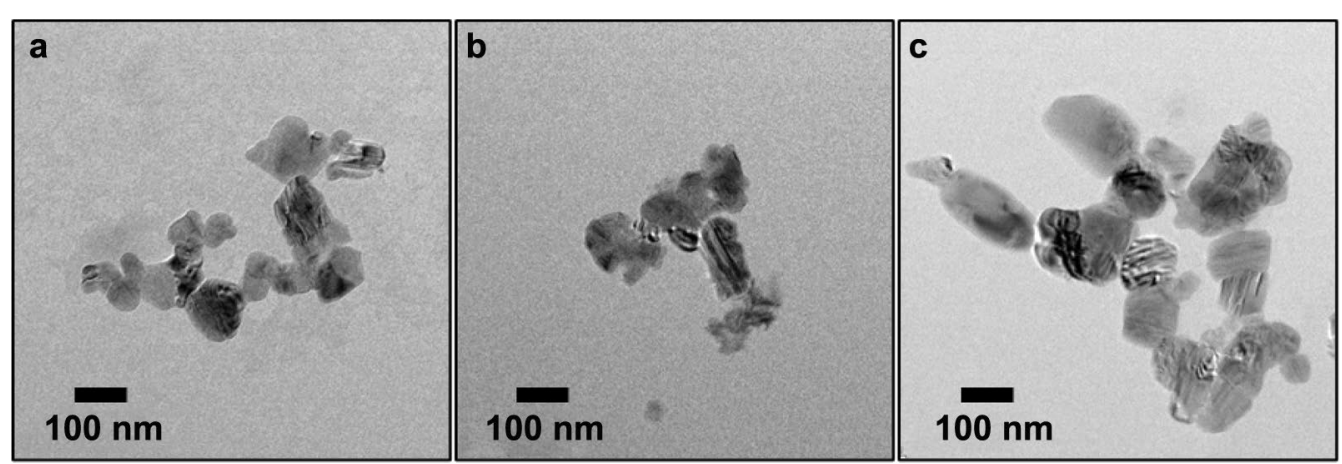

Fig. 3 TEM images of nanoparticles in colloidal solutions prepared by electrolysis at $\mathbf{a} 25^{\circ} \mathrm{C}, \mathbf{b} 35^{\circ} \mathrm{C}$, and $\mathbf{c} 45^{\circ} \mathrm{C}$ 


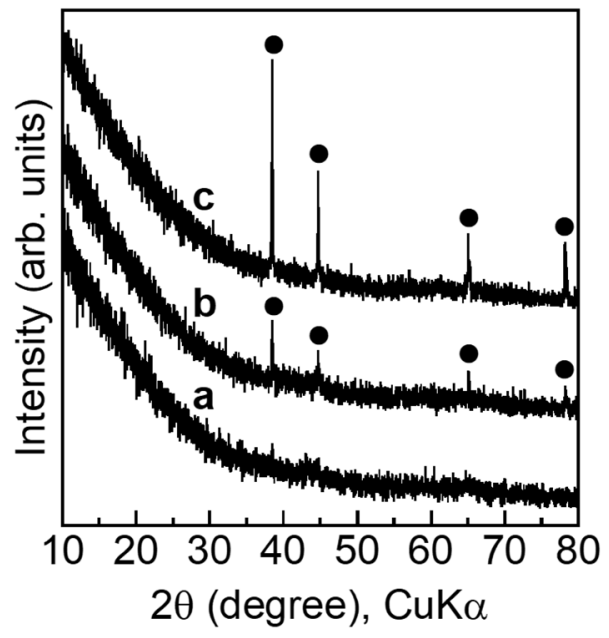

Fig. 4 XRD patterns for nanoparticles in colloidal solutions prepared by electrolysis at a $25^{\circ} \mathrm{C}, \mathbf{b} 35^{\circ} \mathrm{C}$, and $\mathbf{c} 45^{\circ} \mathrm{C}$. : cubic $\mathrm{Al}$

energy at higher temperatures, which resulted in aggregation of the nanoparticles and an increase of the average particle size.

Figure 4 shows the XRD results. Profile (b) is for particles produced at $35{ }^{\circ} \mathrm{C}$. Peaks were detected at $38.5^{\circ}$, $44.7^{\circ}, 65.1^{\circ}$, and $78.2^{\circ}$. These peaks were assigned to the (111), (200), (220), and (311) planes of metallic Al (cubic), respectively, according to previously published results $[26,33]$ and an ICDD reference pattern (\#00-004-0787). These peak assignments confirmed the production of metallic Al particles. An increase in temperature during electrolysis was considered to promote reduction of $\mathrm{Al}^{3+}$ ions and crystallization of particles. By applying the Scherrer equation to the XRD linewidth for the (111) plane peak, we determined that the average metallic $\mathrm{Al}$ crystal size was $55.7 \mathrm{~nm}$. The observed particle size is larger than the crystal size determined by XRD analysis, although they are similar. This result suggests that the metallic Al particles were a mixture of single crystals and polycrystals of metallic Al. However, the formation of a single crystals cannot be confirmed from XRD powder diffraction analysis alone, and analyses using other analytical techniques, such as electron-backscatter diffractometry and selected-area electron diffractometry, are required to demonstrate the formation of a single crystal.

Profile (c) in Fig. 4 is for nanoparticles produced at $45^{\circ} \mathrm{C}$. Peaks assigned to the (111), (200), (220), and (311) planes of metallic $\mathrm{Al}$ (cubic) appeared at $38.5^{\circ}, 44.7^{\circ}$, $65.1^{\circ}$, and $78.2^{\circ}$, respectively. The average $\mathrm{Al}$ crystal size was $59.3 \mathrm{~nm}$; in this case also, the particle size was larger than the crystal size but the sizes were similar. The metallic $\mathrm{Al}$ nanoparticles were similarly speculated to be a mixture of single crystals and polycrystals of metallic Al.
The crystal size increased from 55.7 to $59.3 \mathrm{~nm}$ when the temperature was increased from 35 to $45{ }^{\circ} \mathrm{C}$. This temperature dependence of the particle size reconfirms that higher temperatures promote the crystallization of particles. Notably, no peaks attributable to phases other than metallic $\mathrm{Al}$ (e.g., $\mathrm{Al}$ oxide) were observed in the XRD profiles for the products obtained at either temperature. According to Rai et al. [34], oxidation of metallic Al occurs via the diffusion of oxygen. Such oxidation was not observed in the present work, which indicates that the obtained metallic $\mathrm{Al}$ particles were chemically stable, although the mechanism for this high chemical stability remains unclear.

\section{Gas evolution}

Bubbles were generated on the anode in all the electrolysis experiments. The reaction $2 \mathrm{H}_{2} \mathrm{O} \rightarrow \mathrm{O}_{2}+4 \mathrm{H}^{+}+4 \mathrm{e}^{-}$, which results in gas evolution, must have occurred because the electrolyte solutions contained no substances prone to oxidation other than water. The standard potential of the reaction $\mathrm{O}_{2}+4 \mathrm{H}^{+}+4 \mathrm{e}^{-} \rightleftharpoons 2 \mathrm{H}_{2} \mathrm{O}$ is $+1.229 \mathrm{~V}$ [35]; thus, the reaction $2 \mathrm{H}_{2} \mathrm{O} \rightarrow \mathrm{O}_{2}+4 \mathrm{H}^{+}+4 \mathrm{e}^{-}$does not progress easily. Because electrons in the anode moved toward the power supply via current flow, electrons were depleted at the anode. Therefore, the reaction $2 \mathrm{H}_{2} \mathrm{O} \rightarrow \mathrm{O}_{2}+4 \mathrm{H}^{+}+4 \mathrm{e}^{-}$progressed to the right, which led to $\mathrm{O}_{2}$ evolution at the anode. Thus, the bubbles were regarded as $\mathrm{O}_{2}$ gas produced by the oxidation of water. Because the current flow was provided by electrons generated by both the reactions $2 \mathrm{H}_{2} \mathrm{O} \rightarrow \mathrm{O}_{2}+4 \mathrm{H}^{+}+4 \mathrm{e}^{-}$ and $\mathrm{Al} \rightarrow \mathrm{Al}^{3+}+3 \mathrm{e}^{-}$at the anode, the $\mathrm{O}_{2}$ evolution that resulted from the reaction $2 \mathrm{H}_{2} \mathrm{O} \rightarrow \mathrm{O}_{2}+4 \mathrm{H}^{+}+4 \mathrm{e}^{-}$ would have disturbed the reaction $\mathrm{Al} \rightarrow \mathrm{Al}^{3+}+3 \mathrm{e}^{-}$at the anode. Thus, $\mathrm{O}_{2}$ evolution may have reduced the efficiency of the production of metallic $\mathrm{Al}$ particles because this disturbance did not supply $\mathrm{Al}^{3+}$ ions to the electrolyte solution. The development of a highly efficient method for synthesizing metallic Al particles is a challenge and will be addressed in future work.

\section{Conclusions}

A method for fabricating metallic $\mathrm{Al}$ particles in aqueous solution was proposed. An aqueous colloidal solution of metallic $\mathrm{Al}$ nanoparticles with a cubic crystal structure was prepared by reducing $\mathrm{Al}^{3+}$ ions via electrolysis onto metallic Al-plate electrodes under ultrasonic irradiation and heating. The particle sizes were $76.3 \mathrm{~nm}$ at $25{ }^{\circ} \mathrm{C}, 77.0 \mathrm{~nm}$ at $35{ }^{\circ} \mathrm{C}$, and $84.7 \mathrm{~nm}$ at $45{ }^{\circ} \mathrm{C}$, and the crystal sizes were $55.7 \mathrm{~nm}$ at $35^{\circ} \mathrm{C}$ and $59.3 \mathrm{~nm}$ at $45^{\circ} \mathrm{C}$. Higher temperatures led to greater collisions among the nanoparticles, which promoted particle growth followed by crystal growth. The metallic $\mathrm{Al}$ particles were chemically stable not only in aqueous solution but also in air. 
In conclusion, we demonstrated that chemically stable and colloidally stable metallic Al particles can be synthesized via electrolysis in water. Our future challenge is to develop a highly efficient synthesis method.

\section{Abbreviations}

TEM: Transmission electron microscopy; XRD: X-ray diffraction.

\section{Acknowledgements}

The authors are indebted to Mr. S. Furukawa, who energetically analyzed the measurement results.

\section{Authors' contributions}

TH synthesized the samples, performed all the characterizations, and drafted the manuscript, under TY, NY, KN, and YK's supervision. TY, NY, KN, and YK modified and finished the manuscript. All authors read and approved the final manuscript.

\section{Funding}

No funding was received.

\section{Availability of data and materials}

The datasets supporting the conclusions of this article are included within the article.

\section{Declarations}

Ethics approval and consent to participate

Not applicable.

\section{Consent for publication}

Not applicable.

\section{Competing interests}

The authors declare that they have no competing interests.

\section{Author details}

${ }^{1}$ Department of Materials Science and Engineering, Graduate School of Science and Engineering, Ibaraki University, 4-12-1 Naka-narusawa-cho, Hitachi, Ibaraki 316-8511, Japan. ${ }^{2}$ Central Research Institute, Mitsubishi Materials Corporation, 1002-14 Mukohyama, Naka, Ibaraki 311-0102, Japan.

Received: 19 April 2021 Accepted: 2 December 2021 Published online: 08 December 2021

\section{References}

1. Serra-Maia R, Chastka S, Bellier M, Douglas T, Rimstidt JD, Michel FM (2019) Effect of particle size on catalytic decomposition of hydrogen peroxide by platinum nanocatalysts. J Catal 373:58-66

2. Sharma P, Semwal V, Gupta BD (2019) A highly selective LSPR biosensor for the detection of taurine realized on optical fiber substrate and gold nanoparticles. Opt Fiber Technol 52:101962

3. Munir T, Mahmood A, Imran M, Sohail A, Fakhar-e-Alam M, Sharif M, Masood T, Bajwa SZ, Shafiq F, Latif S (2021) Quantitative analysis of glucose by using (PVP and MA) capped silver nanoparticles for biosensing applications. Phys B 602:412564

4. Pourmortazavi SM, Hajimirsadeghi SS, Kohsari I, Fathollahi M, Hosseini SG (2008) Thermal decomposition of pyrotechnic mixtures containing either aluminum or magnesium powder as fuel. Fuel 87:244-251

5. Bunker CE, Smith MJ, Fernando KAS, Harruff BA, Lewis WK, Gord JR, Guliants EA, Phelps DK (2010) Spontaneous hydrogen generation from organic-capped Al nanoparticles and water. ACS Appl Mater Interfaces 2:11-14
6. Karlsson PM, Baeza A, Palmqvist AEC, Holmberg K (2008) Surfactant inhibition of aluminium pigments for waterborne printing inks. Corr Sci 50:2282-2287

7. Kwon YS, Gromov AA, llyin AP, Rim GH (2003) Passivation process for superfine aluminum powders obtained by electrical explosion of wires. Appl Surf Sci 211:57-67

8. Ishihara S, Suematsu H, Nakayama T, Suzuki T, Niihara K (2012) Synthesis of nanosized alumina powders by pulsed wire discharge in air flow atmosphere. Ceram Int 38:4477-4484

9. Mandilas C, Daskalos E, Karagiannakis G, Konstandopoulos AG (2013) Synthesis of aluminium nanoparticles by arc plasma spray under atmospheric pressure. Mater Sci Eng B 178:22-30

10. Mathe VL, Varma V, Raut S, Nandi AK, Pant A, Prasanth H, Pandey RK, Bhoraskar SV, Das AK (2016) Enhanced active aluminum content and thermal behaviour ofnano-aluminum particles passivated during synthesis using thermal plasma route. Appl Surf Sci 368:16-26

11. Lerner MI, Glazkova EA, Lozhkomoev AS, Svarovskaya NV, Bakina OV, Pervikov AV, Psakhie SG (2016) Synthesis of Al nanoparticles and AI/AIN composite nanoparticles by electrical explosion of aluminum wires in argon and nitrogen. Powder Technol 295:307-314

12. Abdelkader EM, Jelliss PA, Buckner SW (2016) Main group nanoparticle synthesis using electrical explosion of wires. Nano-Struct Nano-Obj 7:23-31

13. Yi Z, Xu X, Luo J, Li X, Yi Y, Jiang X, Yi Y, Tang Y (2014) Size controllable synthesis of ultrafine spherical gold particles and their simulation of plasmonic and SERS behaviors. Phys B 438:22-28

14. Huff C, Biehler E, Quach Q, Long JM, Abdel-Fattah TM (2021) Synthesis of highly dispersive platinum nanoparticles and their application in a hydrogen generation reaction. Colloids Surf A 610:125734

15. Liu T, Li D, Yang D, Jiang M (2011) Size controllable synthesis of ultrafine silver particles through a one-step reaction. Mater Lett 65:628-631

16. Nie H, Schoenitz M, Dreizin EL (2012) Calorimetric investigation of the aluminum-water reaction. Int J Hydrog Energy 37:11035-11045

17. Ghanta SR, Muralidharan K (2013) Chemical synthesis of aluminum nanoparticles. J Nanopart Res 15:1715

18. Cui Y, Zhao S, Tao D, Liang Z, Huang D, Xu Z (2014) Synthesis of sizecontrolled and discrete core-shell aluminum nanoparticles with a wet chemical process. Mater Lett 121:54-57

19. Falola BD, Suni II (2015) Low temperature electrochemical deposition of highly active elements. Curr Opin Solid State Mater Sci 19:77-84

20. Pereira NM, Pereira CM, Araujo JP, Silva AF (2017) Zinc electrodeposition from deep eutectic solvent containing organic additives. J Electroanal Chem 801:545-551

21. Yapontseva YS, Kublanovsky VS, Vyshnevskyi OA (2018) Electrodeposition of CoMoRe alloys from a citrate electrolyte. J Alloys Compd 766:894-901

22. Wang X, Han Y, Zhang J, Li Z, Li T, Zhao X, Liu W (2019) Influence of electropolished copper substrate on morphology of electroplating selfsupporting Ni films. Nucl Instrum Meth Phys Res A 927:343-348

23. Lee H, Tsai ST, Wu PH, Dow WP, Chen CM (2019) Influence of additives on electroplated copper films and their solder joints. Mater Charact 147:57-63

24. Shavkunov SP, Strugova TL (2003) Electrode processes during aluminum electrodeposition in aromatic solvents. Russ J Electrochem 39:642-649

25. Jiang T, Chollier Brym MJ, Dubé G, Lasia A, Brisard GM (2007) Studies on the $\mathrm{AlCl}_{3} /$ dimethylsulfone (DMSO$)$ ) electrolytes for the aluminum deposition processes. Surf Coat Technol 201:6309-6317

26. Yue G, Lu X, Zhu Y, Zhang X, Zhang S (2009) Surface morphology, crystal structure and orientation of aluminium coatings electrodeposited on mild steel in ionic liquid. Chem Eng J 147:79-86

27. Shen Q, Min Q, Shi J, Jiang L, Hou W, Zhu JJ (2011) Synthesis of stabilizerfree gold nanoparticles by pulse sonoelectrochemical method. Ultrason Sonochem 18:231-237

28. Zin V, Pollet BG, Dabalà M (2009) Sonoelectrochemical $(20 \mathrm{kHz})$ production of platinum nanoparticles from aqueous solutions. Electrochim Acta 54:7201-7206

29. Zhu J, Liu S, Palchik O, Koltypin Y, Gedanken A (2000) Shape-controlled synthesis of silver nanoparticles by pulse sonoelectrochemical methods. Langmuir 16:6396-6399

30. Abedin SZE, Moustafa EM, Hempelmann R, Natter H, Endres F (2005) Additive free electrodeposition of nanocrystalline aluminium in a water and air stable ionic liquid. Electrochem Commun 7:1111-1116 
31. Mahendiran C, Ganesan R, Gedanken A (2009) Sonoelectrochemical synthesis of metallic aluminum nanoparticles. Eur J Inorg Chem. https:// doi.org/10.1002/ejic.200900097

32. Cretković VS, Vukićević NM, Jovićević N, Stevanović JS, Jovićević JN (2020) Aluminium electrodeposition under novel conditions from $\mathrm{AlCl}_{3}$-urea deep eutectic solvent at room temperature. Trans Nonferrous Met Soc China 30:823-834

33. Liang L, Guo X, Liao X, Chang Z (2020) Improve the interfacial adhesion, corrosion resistance and combustion properties of aluminum powder by modification of nickel and dopamine. Appl Surf Sci 508:144790

34. Rai A, Park K, Zhou L, Zachariah MR (2006) Understanding the mechanism of aluminium nanoparticle oxidation. Combust Theory Model 10:843-859

35. Bard AJ, Faulkner LR (1980) Electrochemical methods: fundamentals and applications. Wiley, New York

\section{Publisher's Note}

Springer Nature remains neutral with regard to jurisdictional claims in published maps and institutional affiliations.

\section{Submit your manuscript to a SpringerOpen ${ }^{\circ}$ journal and benefit from:}

- Convenient online submission

- Rigorous peer review

- Open access: articles freely available online

- High visibility within the field

- Retaining the copyright to your article

Submit your next manuscript at $\boldsymbol{\nabla}$ springeropen.com 